International Journal of Rotating Machinery

2001, Vol. 7, No. 1, pp. 53-63

Reprints available directly from the publisher

Photocopying permitted by license only
(6) 2001 OPA (Overseas Publishers Association) N.V.

Published by license under the Gordon and Breach Science Publishers imprint. Printed in Malaysia.

\title{
3-D Viscous Flow Analysis of a Mixed Flow Pump Impeller
}

\author{
STEVEN M. MINER* \\ Mechanical Engineering Department, United States Naval Academy, Annapolis, MD 21402, USA
}

(Received 30 July 1999; In final form 27 August 1999)

\begin{abstract}
This paper presents the results of a study using a coarse grid to analyze the flow in the impeller of a mixed flow pump. A commercial computational fluid dynamics code (FLOTRAN) is used to solve the 3-D Reynolds Averaged Navier Stokes equations in a rotating cylindrical coordinate system. The standard $k-\varepsilon$ turbulence model is used. The mesh for this study uses 26,000 nodes and the model is run on a SPARCstation 20. This is in contrast to typical analyses using in excess of 100,000 nodes that are run on a super computer platform. The smaller mesh size has advantages in the design environment. Stage design parameters are, rotational speed $1185 \mathrm{rpm}$, flow coefficient $\phi=0.116$, head coefficient $\psi=0.094$, and specific speed 2.01 (5475 US). Results for the model include circumferentially averaged results at the leading and trailing edges of the impeller, and analysis of the flow field within the impeller passage. Circumferentially averaged results include axial and tangential velocities, static pressure, and total pressure. Within the impeller passage the static pressure and velocity results are presented on surfaces from the leading edge to the trailing edge, the hub to the shroud, and the pressure surface to the suction surface. Results of this study are consistent with the expected flow characteristics of mixed flow impellers, indicating that small CFD models can be used to evaluate impeller performance in the design environment.
\end{abstract}

Keywords: Pump, Mixed flow, 3-D, Viscous, Impeller

\section{INTRODUCTION}

Designers are continually being challenged to provide pumps that operate more efficiently, quietly, and reliably at lower cost. Key to building these machines is a better understanding of, and ability to predict their hydraulic and dynamic characteristics. Understanding and predicting these characteristics requires a detailed knowledge of the flow fields within the stationary and rotating passages of the pump. With the advent of more powerful computers, computational fluid dynamics (CFD) is seeing more and more use in predicting the flow fields in both the stationary and rotating passages of turbomachines. Lakshminarayana (1991) provides a review of the techniques that are currently

\footnotetext{
* Tel.: 410293 6527. Fax: 410293 2591. E-mail: miner@usna.navy.mil.
} 
being used, as well as, an assessment of the state of the art.

Most of the previous work in this area has been for compressible flow, and was driven by the gas turbine industry. Adamczyk et al. (1989), and Furukawa et al. (1991) are typical examples. Examples of incompressible studies are $\mathrm{Yu}$ et al. (1995), and Yang (1995). In both cases, compressible and incompressible flow, the solutions have been obtained using codes that are developed in house, using meshes that have in excess of 100,000 nodes, and are run on super computer platforms. The hardware and time requirements for models of this size are not suitable for use in day to day design applications.

The present work uses FLOTRAN to obtain solutions for the flow field and pressure field within the impeller of a mixed flow pump. The code is run on a Sun SPARCstation 20, and the model size is approximately 26,000 nodes. Turn around time for geometry update and solution is one day, which makes the use of the code in the design process feasible. Results presented here include circumferentially averaged velocity and pressure profiles at the leading and trailing edges of the impeller. In addition, velocity and static pressure distribution data are presented on surfaces from the leading edge to the trailing edge, the hub to the shroud, and the pressure surface to the suction surface. This study is a continuation of work performed by White et al. (1993), and Miner (1996), which considered an axial flow impeller. The mixed flow geometry is being evaluated because of its increase in head coefficient.

\section{CFD FORMULATION}

FLOTRAN is a finite element based code which solves the Reynolds Averaged Navier Stokes equations in primitive variable form. Turbulence is modeled using the $k-\varepsilon$ turbulence model, with the $\log$ law of the wall to simulate the boundary layers. The formulation of the code is based on the SIMPLER method of Patankar (1980). For the impeller analysis discussed in this paper the equations governing the turbulent incompressible flow are formulated in a rotating reference frame. The continuity and momentum equations become:

$$
\begin{gathered}
\nabla \cdot(\rho \mathbf{U})+\frac{\partial \rho}{\partial t}=0, \\
\frac{D(\rho \mathbf{U})}{D t}+2 \rho \boldsymbol{\omega} \times \mathbf{U}+\rho \boldsymbol{\omega} \times \boldsymbol{\omega} \times \mathbf{r} \\
=\rho \mathbf{g}-\nabla P+\mu_{\mathrm{e}} \nabla^{2} \mathbf{U},
\end{gathered}
$$

where $P$ is modified to account for effects due to rotation, and $\mu_{\mathrm{e}}$ the linear combination of the kinematic viscosity and the turbulent viscosity derived from the $k-\varepsilon$ model. These equations along with the appropriate boundary conditions are solved for the three components of velocity and the pressure. Boundary conditions used for this analysis include stationary and moving walls, specified inlet velocities, specified outlet pressure, and periodic boundaries.

\section{GEOMETRY}

Figure 1 shows a cross section view of the pump, which is described in detail by White et al. (1993), the only difference being that the axial flow impellers have been replaced by mixed flow impellers. The pump is a two stage design with an impeller and stator making up each stage. The impellers are contra-rotating. The analysis presented in this paper is for the first stage impeller only. Design parameters for the stage are rotational speed $1185 \mathrm{rpm}$, flow rate $0.38 \mathrm{~m}^{3} / \mathrm{s}$, and head rise $13.1 \mathrm{~m}$. These result in the following nondimensional parameters, flow coefficient $\phi=0.116$, head coefficient $\psi=0.094$, and specific speed 2.01 (5475 US). Figure 2 shows a perspective view of the impeller. This particular impeller has the shroud attached to the blade tips, which eliminates the blade tip leakage flow. The hub radius varies from $0.037 \mathrm{~m}$ at the leading edge to $0.107 \mathrm{~m}$ at the trailing edge. 


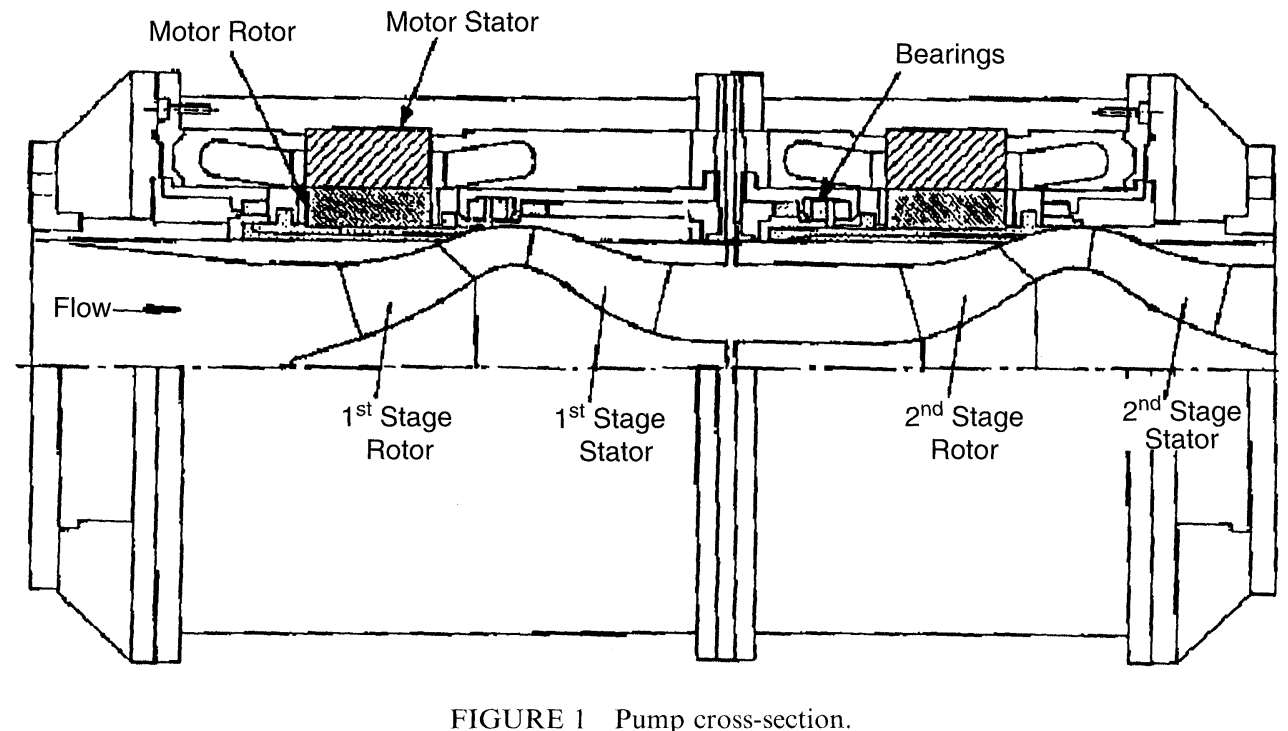

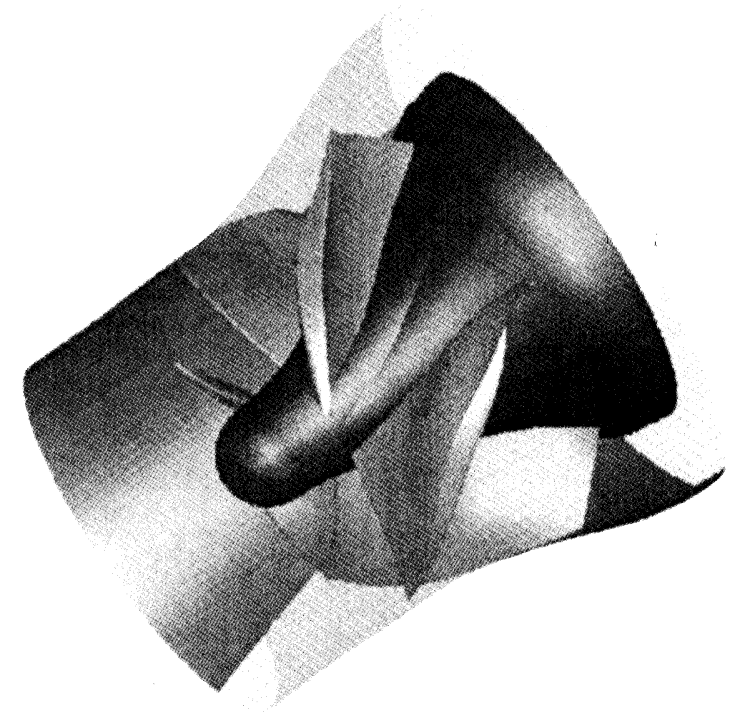

FIGURE 2 Pump impeller.

The shroud radius varies from $0.126 \mathrm{~m}$ at the leading edge to $0.149 \mathrm{~m}$ at the trailing edge. The Reynold's number based on the blade tip speed at the trailing edge is $1.7 \times 10^{6}$.

Due to symmetry, only one of the blade passages needs to be analyzed. Figure 3 illustrates this blade passage with the appropriate upstream and downstream extensions. This becomes the geometry that is modeled in the rotating reference frame. At the inlet to the domain the axial velocity is a constant based on the through flow for the pump. The absolute tangential velocity at the inlet is zero, which implies in the rotating frame the relative velocity is $-r \omega$, and the radial velocity is zero. The inlet to the solution domain is located approximately twelve chord lengths upstream of the blade leading edge. The only specification made at the outlet is that the static pressure in the absolute frame is uniform and set to zero. This absolute condition is converted into the appropriate relative pressure in the rotating frame. This condition is applied roughly sixteen chord lengths downstream of the blade trailing edge. Periodic boundaries are used upstream and downstream of the blade leading and trailing edges, respectively. For the rotating solid surfaces all of the velocity components are set to zero. This includes all the surfaces within the blade passage, the nose cone portion of the hub upstream of the blade leading edge, and a short section of the hub, $40 \%$ of chord length, downstream of the trailing edge. The shroud surfaces upstream and downstream of the blade passage, and the remaining hub surface downstream are stationary in the absolute reference frame. 


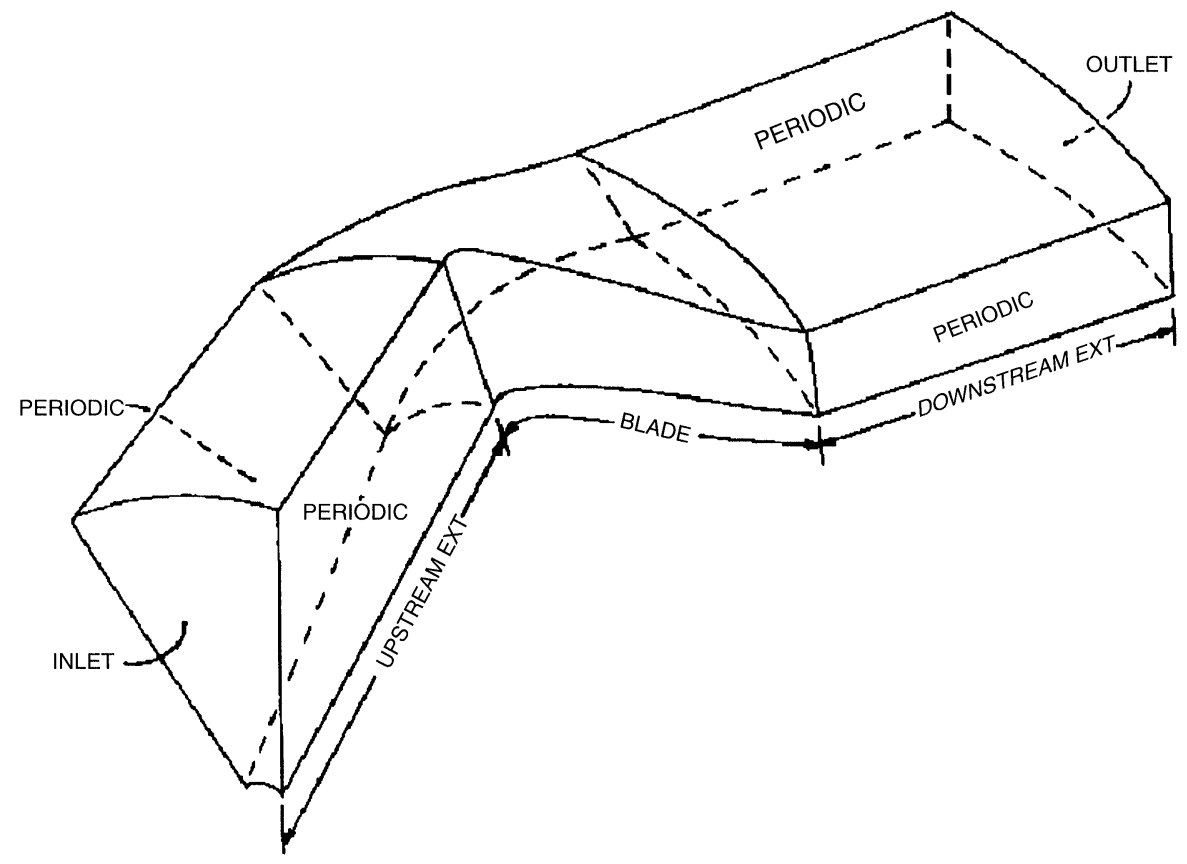

FIGURE 3 Solution domain

In the rotating frame they are treated as moving boundaries with the axial and radial components of velocity set to zero and the tangential component set equal to $-r_{0} \omega$ for the shroud, and $-r_{i} \omega$ for the hub.

The selection of an appropriate mesh density for this study is based on the previous analysis of an axial flow impeller by Miner (1996). In that study two meshes were considered, one with 22,176 nodes and the other with 40,131 nodes. Comparison of the velocity profiles from the two meshes showed no significant differences. Therefore, it was determined that the coarse mesh provided sufficient resolution. In addition, the computational results for the coarse mesh were compared to measured data for the axial flow impeller. The largest difference between the measured and computed data was $15 \%$ in the tangential velocity profile. This difference was due primarily to a difference in the downstream boundary condition used in the model and the conditions downstream of the measured impeller. The computational model considered only the first stage impeller, whereas the measured data was collected with both of the impellers in place. The experience gained in the analysis of the axial flow impeller was used as the basis for establishing the mesh density in the present analysis, which has 26,299 nodes. There are 17 nodes blade to blade, 17 nodes hub to shroud, and 91 nodes inlet to outlet, of which 31 are in the blade passage. The nodes are spaced more closely near the hub, shroud, and blade surfaces, as well as, near the leading and trailing edges. The value for $y^{+}$is between 400 and 600 throughout the blade passage. This value indicates that the near wall nodes are not within the laminar sublayer but are within the overlap layer of the turbulent boundary layer. Therefore, the application of the log law of the wall formulation is appropriate.

The time required to generate the completed FEA model was approximately $8 \mathrm{~h}$, the solution for the initial geometry required 500 iterations and $85 \mathrm{~h}$ of CPU time. Subsequent updates to the geometry and an updated solution could be obtained within 
$24 \mathrm{~h}, 8 \mathrm{~h}$ to modify the model and $15 \mathrm{~h}$ to update the solution. Updated solutions were always started from the previous converged solution. Having a one day turn around time allows CFD analysis to be used in the design process.

\section{RESULTS}

The results presented in this paper include circumferentially averaged velocity and pressure profiles at the leading and trailing edges of the impeller. The averaged velocity results are absolute and nondimensionalized by the trailing edge blade tip velocity $U_{\mathrm{t}}$, the pressures are nondimensionalized by $\rho U_{\mathrm{t}}^{2} / 2$, and the radius is nondimensionalized by the shroud radius at the trailing edge $r_{0}$. In addition, velocity and static pressure distribution data are presented on surfaces from the leading edge to the trailing edge, the hub to the shroud, and the pressure surface to the suction surface.

Figure 4 shows the circumferentially averaged results at the leading edge. These results are taken 0.1 chord lengths upstream of the leading edge. At this upstream location the shroud is not rotating with the impeller. The axial velocity shows a slight deficit at the hub relative to the shroud. This is due to flow having to come up over the nose cone of the impeller. The effect of the nose is also evident in the radial velocity profile, which shows positive velocity from the hub towards the shroud. The tangential profile is nearly zero from the hub to the shroud, with slight preswirl at the shroud surface due to the extension of the shroud upstream of the leading edge. The preswirl is less than $5 \%$ of the tip speed at the leading edge. The static pressure profile
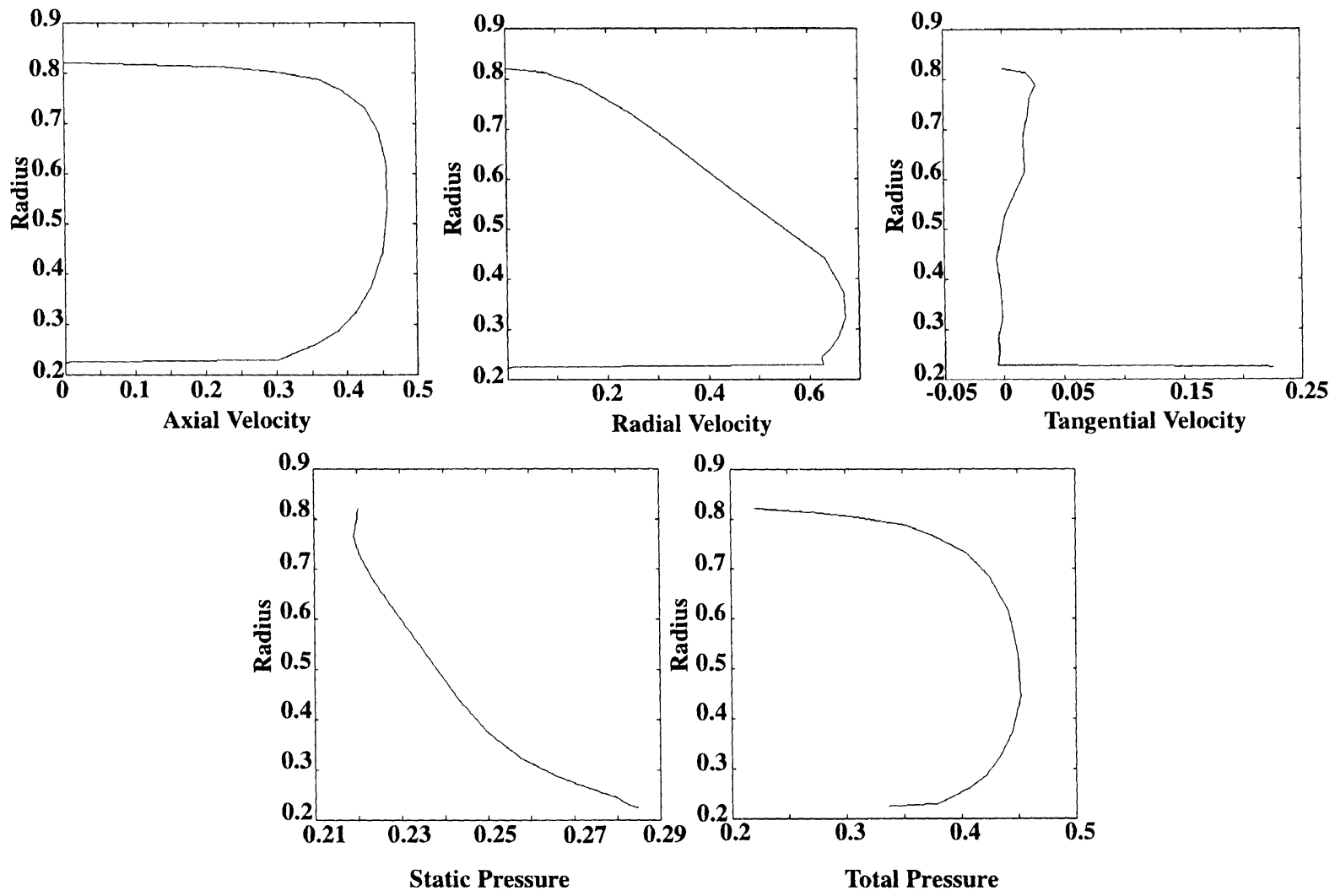

FIGURE 4 Leading edge results. 
shows a drop in pressure from the hub to the shroud surface. This can be understood in terms of the axial and tangential velocity profiles. At the hub both the axial and tangential velocities were lower than the velocities at the shroud, this reduction in velocity produces the rise in static pressure at the hub. The majority of this effect is due to the reduction in the axial velocity.

Figure 5 shows circumferentially averaged results at the trailing edge. These results are taken 0.1 chord lengths downstream of the trailing edge. At this downstream location the shroud is not rotating with the impeller. At the trailing edge the axial velocity profile shows the opposite trend from the leading edge, with the peak velocity shifted down toward the hub. This shift in the axial velocity profile is consistent with the balance between the centrifugal and pressure forces acting on the fluid, that arises through the concept of radial equilibrium.
The radial velocity profile shows larger values at the hub than the shroud, which is due to the shape of the hub. The hub radius changes by a factor of 2.9 from the leading edge to the trailing edge, while the radius of the shroud changes by only a factor of 1.2 . At the trailing edge the variation in the tangential velocity from the hub to the shroud is $\pm 8 \%$ about the mean. The tangential velocity plot also indicates that the boundary layers at the hub and shroud surfaces are thin compared to the passage height The static pressure at the trailing edge increases from the hub to the shroud. This variation in the profile relates primarily to the axial velocity profile with its higher velocity at the hub compared to the shroud. The tangential velocity makes a smaller contribution to the change in pressure from the hub to the shroud. The total pressure at the trailing edge is uniform to within $\pm 4 \%$ of the mean value from the hub to the shroud.
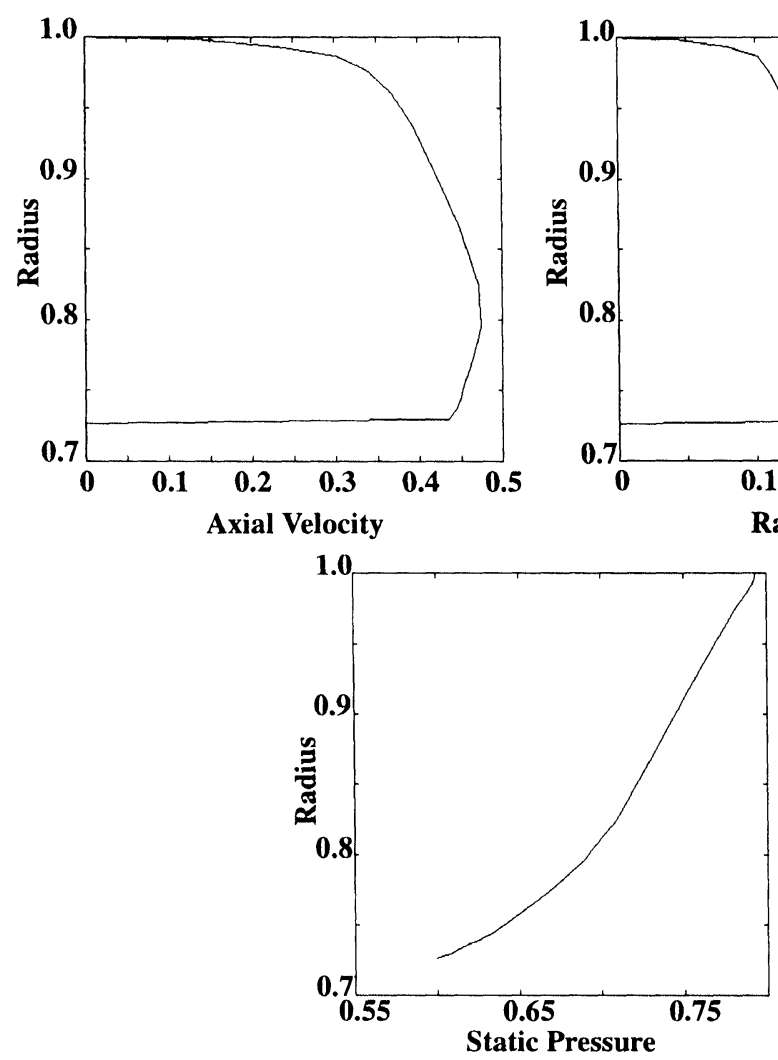
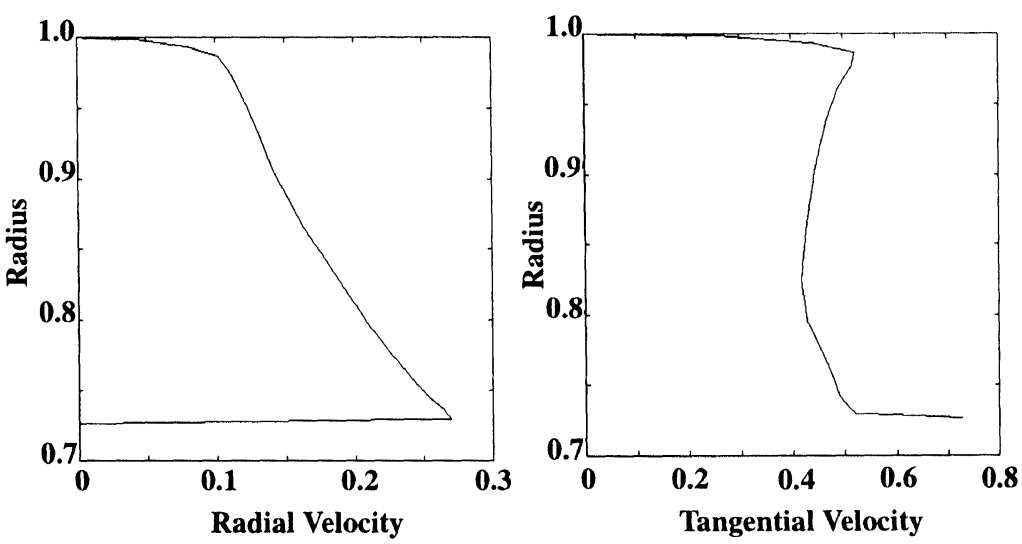

FIGURE 5. Trailing edge results. 
Figures 6 and 7 show axial velocity distributions and static pressure distributions within the impeller passage, respectively. At the leading edge the velocity distribution shows the deficit in flow that was

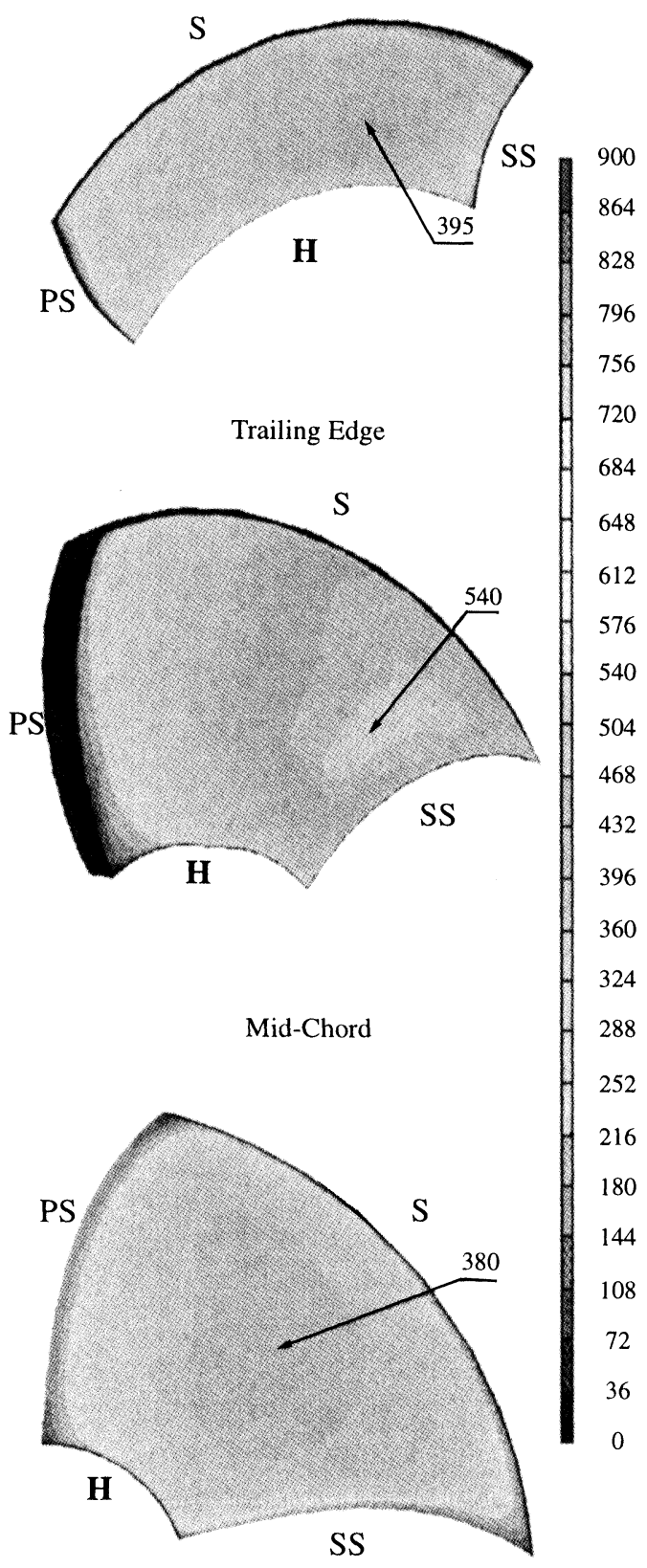

Leading Edge

FIGURE 6 Axial velocity distributions, L.E. to T.E. evident in the circumferentially averaged profile, but it also shows that the velocity at the pressure surface is reduced compared to the velocity at the suction surface. The corresponding pressure plot in

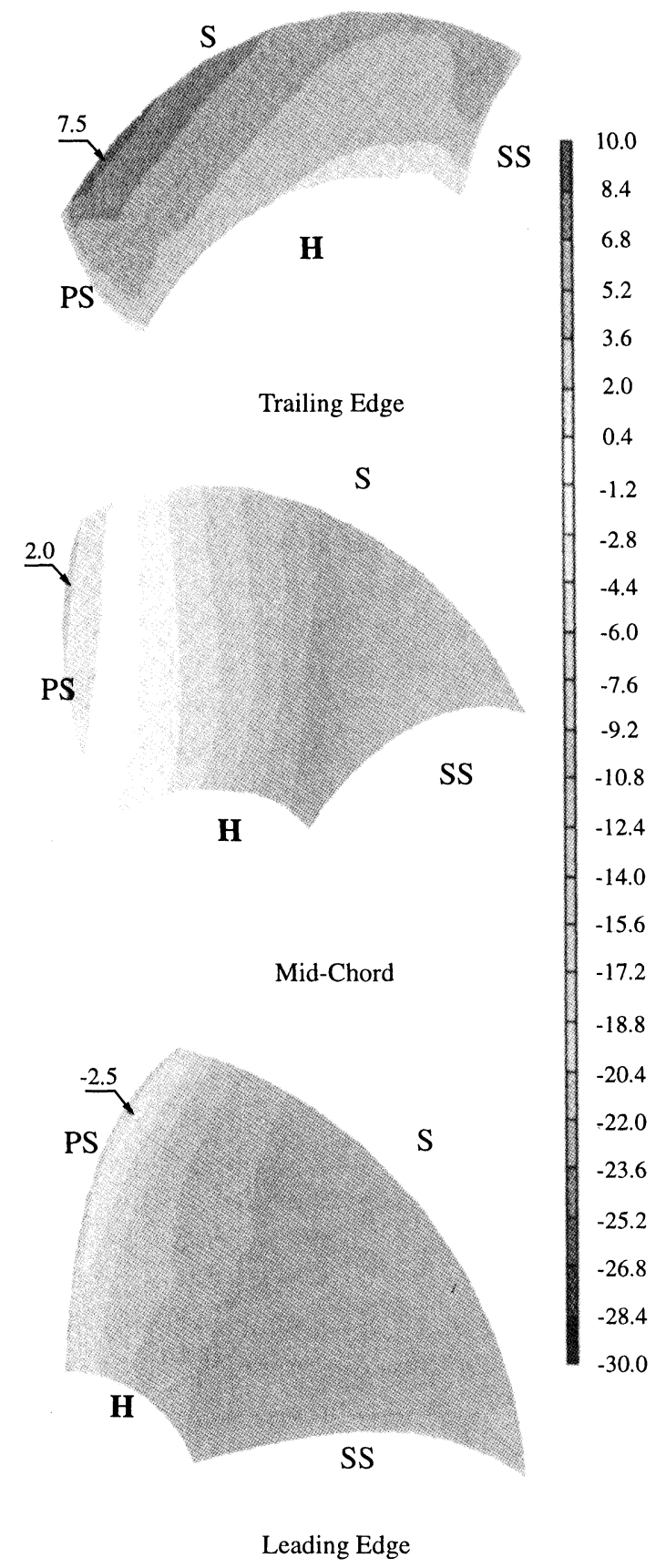

FIGURE 7 Pressure distributions, L.E. to T.E. 
Fig. 7 shows the pressure contours being aligned with the blade surfaces. At the mid-chord location the formation of a jet-wake structure is becoming evident. The lower velocity fluid is accumulating near intersection of the pressure and hub surfaces, with a corresponding high velocity region at the intersection of the suction and shroud surfaces. The pressure plot at mid-chord shows the contours losing alignment with the blade surfaces and being more heavily influenced by the presence of the developing jet-wake structure. At the trailing edge location the development of the jet-wake structure has continued. The low velocity fluid continues to accumulate along the pressure and shroud surfaces, with the high velocity fluid accumulating at the intersection of the hub and suction surfaces. The contours on the pressure plot show that the direction of the gradient is from the pressure/shroud intersection towards the suction/hub intersection, and not directed from the pressure surface to the suction surface. These results are consistent with the jet-wake phenomena and previously published results.

Figures 8 and 9 show relative velocity vectors and pressure contours on surfaces from the hub to the shroud. The velocity results for the hub and shroud surfaces are for the first layer of nodes off of the surfaces. On all three surfaces the high velocity fluid travels along the suction surface, with the velocity being higher at the shroud than the hub. All three surfaces show a low pressure region on the suction surface at about mid-chord where the fluid travels over a convex portion of the blade. Again, the pressure contours show the gradient in pressure at the trailing edge going from the pressure/shroud surface intersection to the suction/hub surface intersection.

Figures 10 and 11 show relative velocity vectors and pressure contours on surfaces from the suction surface to the pressure surface. As with Fig. 8, the velocity results for the pressure and suction surfaces are for the first layer of nodes off of the surface. Here again, the results show the formation of the jet-wake structure.

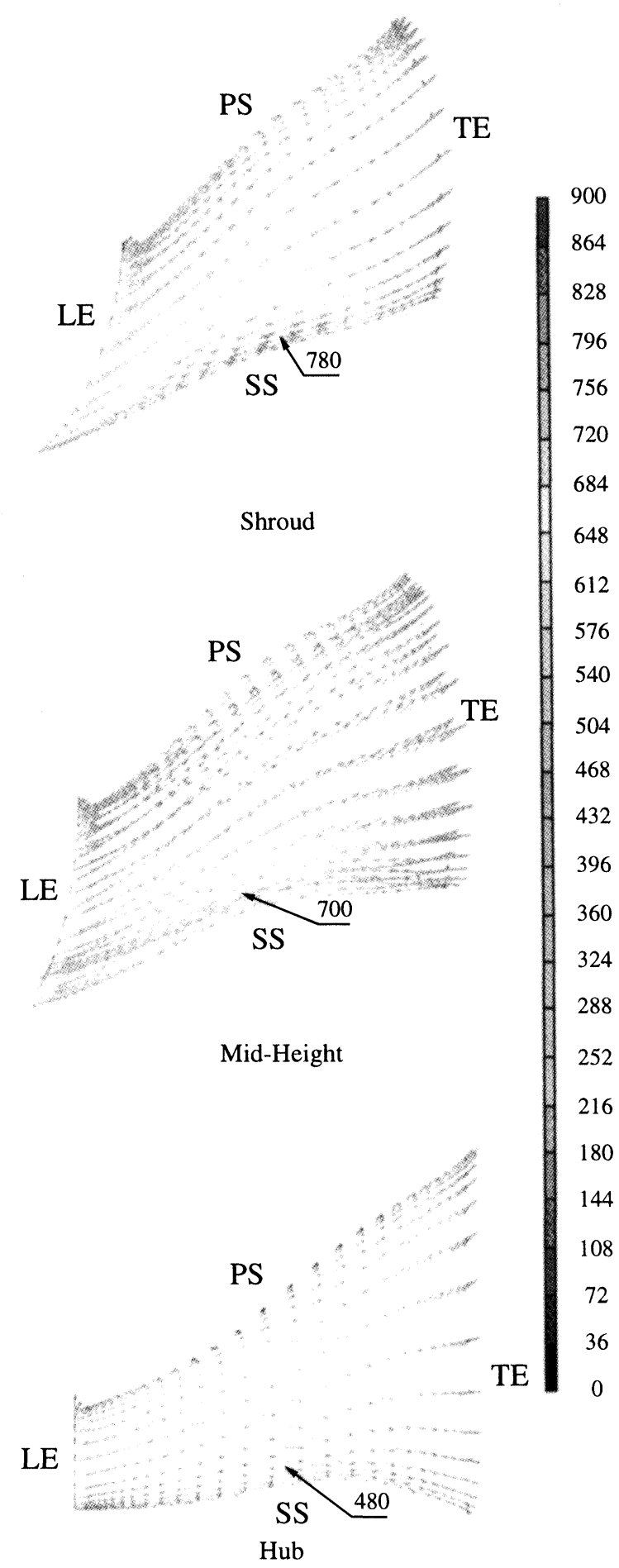

FIGURE 8 Velocity vectors, hub to shroud. 


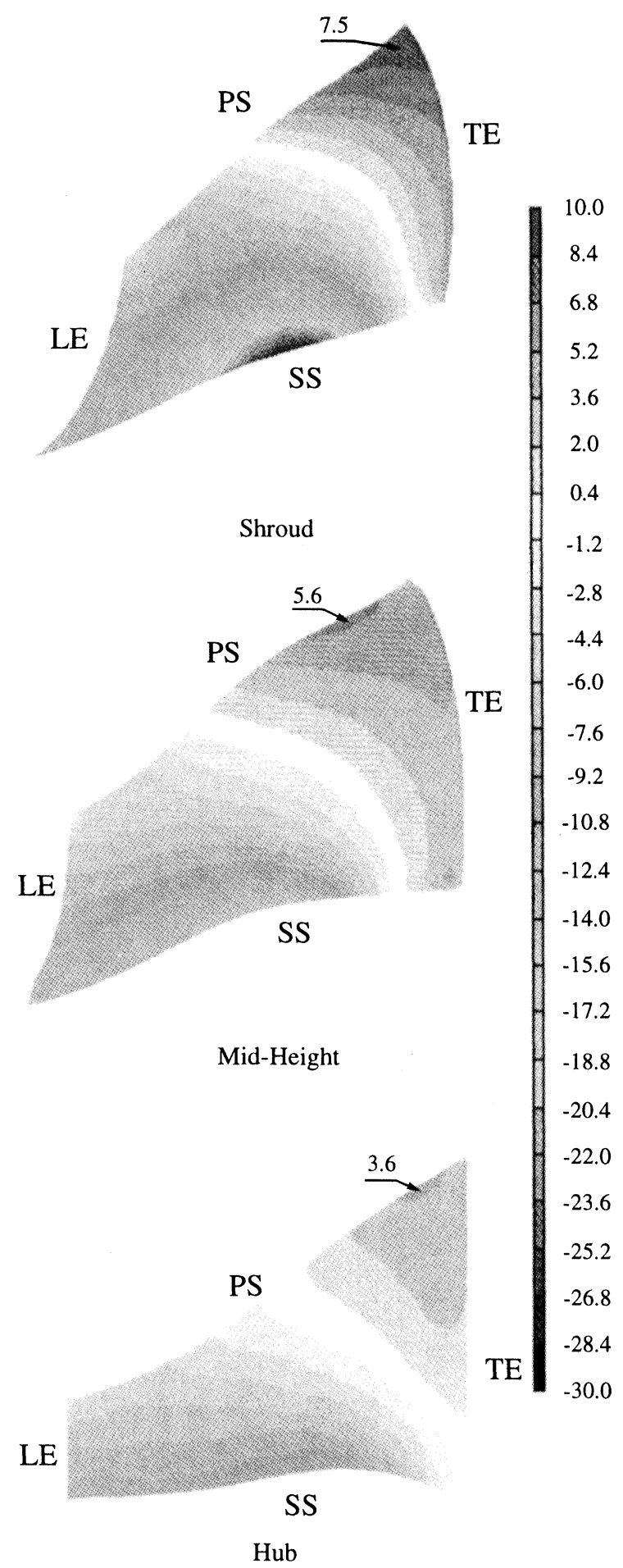

FIGURE 9 Pressure distributions, hub to shroud.

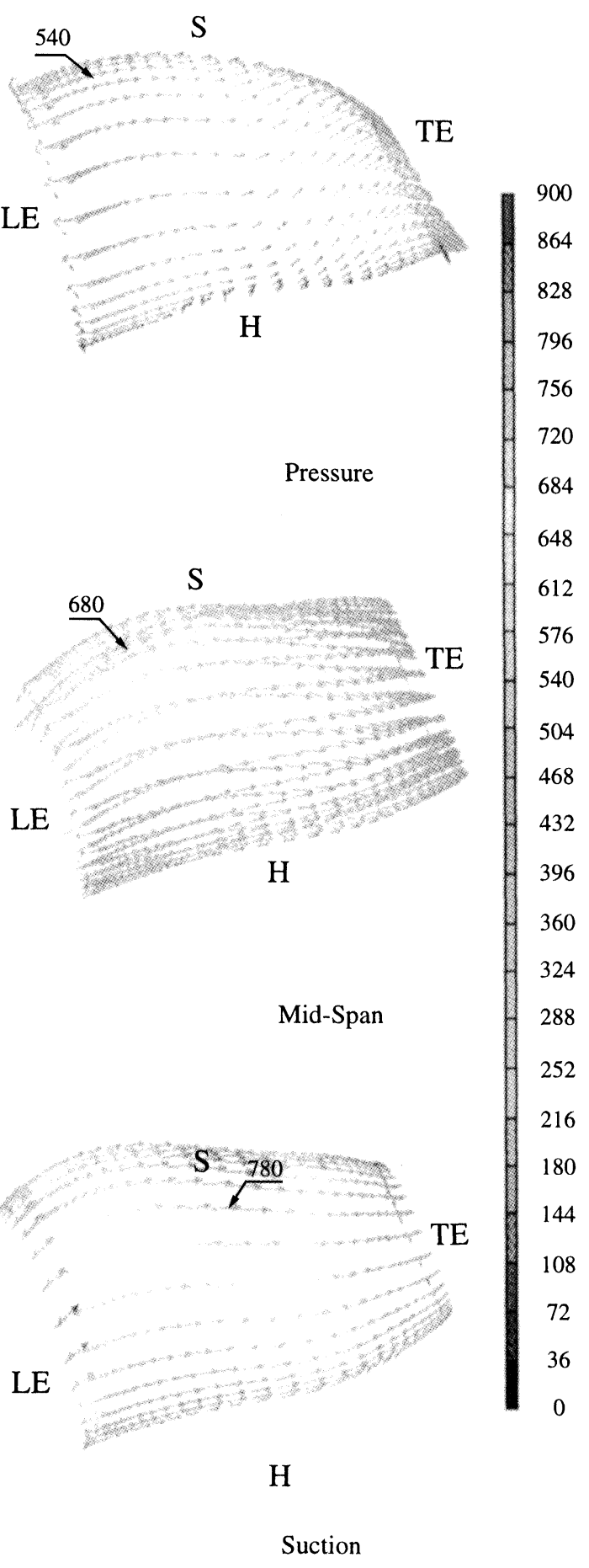

FIGURE 10 Velocity vectors, S.S. to P.S. 


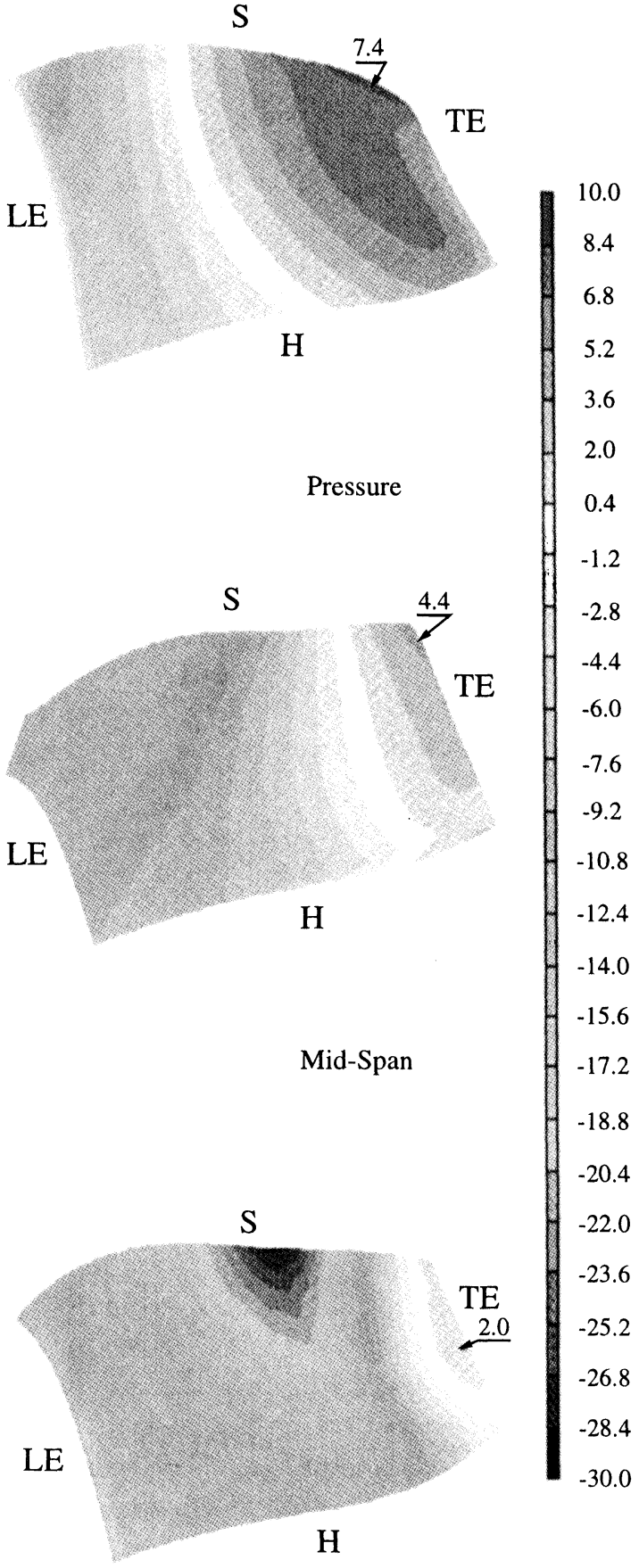

\section{Suction}

FIGURE 11 Pressure distributions, S.S. to P.S.

\section{CONCLUSIONS}

The following conclusions are based on the results of this study:

(1) Results of this study are consistent with the expected flow characteristics of mixed flow impellers.

(2) Both the circumferentially averaged data and the blade passage results provide sufficient detail to evaluate the performance of the impeller.

(3) Using small models, CFD can be used effectively in the design process. Turn around times of one day are possible using a work station.

\section{Acknowledgements}

This work was supported by the Naval Surface Warfare Center, Carderock Division, Annapolis Detachment, and the Naval Academy Research Council.

\section{NOMENCLATURE}

g gravitational vector

$P \quad$ modified static pressure

$r$ radius vector

$r_{i}$ hub radius

$r_{0} \quad$ shroud radius

U velocity vector

$U_{\mathrm{t}} \quad$ blade tip speed

$\mu_{\mathrm{e}} \quad$ effective viscosity

$\rho$ density

$\phi \quad$ flow coefficient

$\psi \quad$ head coefficient

$\boldsymbol{\omega}$ angular velocity vector

\section{References}

Adamczyk, J.J., Celestina, M.L., Beach, T.A. and Barnett, M. (1989) Simulation of 3-D viscous flow within a multi-stage turbine, ASME Paper 89-GT-152.

Furukawa, M., Yamasaki, M. and Inoue, M. (1991) A zonal approach for Navier-Stokes computations of compressible cascade flow fields using a TVD finite volume method, $A S M E$ Journal of Turbomachinery, 113(4), 573-582. 
Lakshminarayana, B. (1991) An assessment of computational fluid dynamic techniques in the analysis and design of turbomachinery - The 1990 Freeman Scholar Lecture, ASME Journal of Fluids Engineering, 113(3), 315-352

Miner, S.M. (1996) 3D viscous flow analysis of an axial flow pump impeller, Proc. 6th Int'l Symp. on Transport Phenomena and Dynamics of Rotating Machinery, ISROMAC-6, Vol. II, pp. 336-344.

Patankar, S.V. (1980) Numerical Heat Transfer and Fluid Flow, Hemisphere, New York, NY.

White, J.W., Purnell, J.G. and Stricker, J.G. (1993) In-line submersible pump, Proceedings of the 2nd ASME Pumping Machinery Symposium, ASME, FED-Vol. 154, pp. 369-375.
Yang, C.I. (1995) A simulation of viscous incompressible flow through a multiple-blade-row turbomachinery with a highresolution upwind finite differencing scheme, Numerical Simulations in Turbomachinery, ASME, FED-227, 11-18.

Yu, W.S., Lakshminarayana, B. and Thompson, D.E. (1995) Computation of three-dimensional viscous flow in high Reynolds number pump guide vane, Numerical Simulation in Turbomachinery, ASME, FED-227, 117-122. 

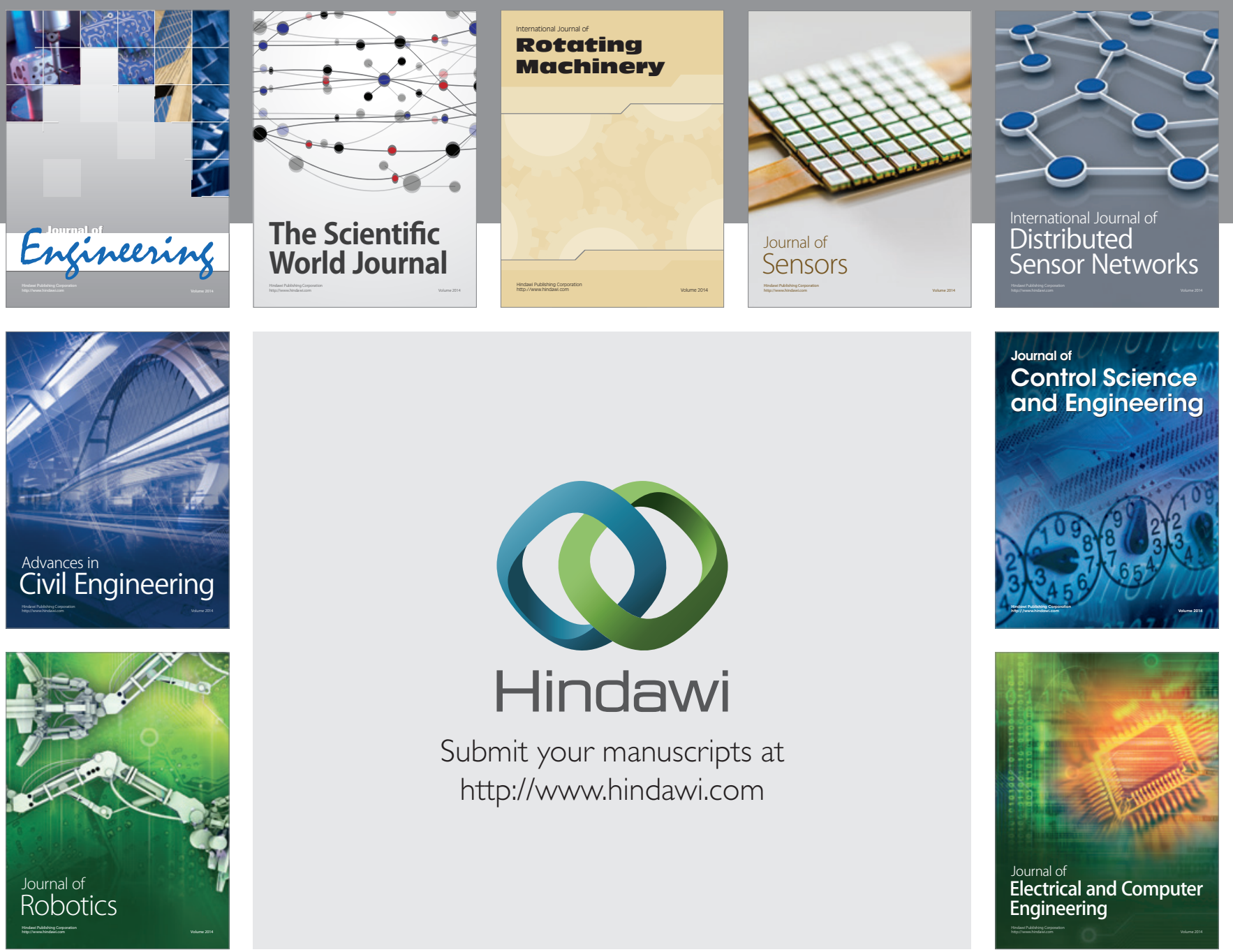

Submit your manuscripts at

http://www.hindawi.com
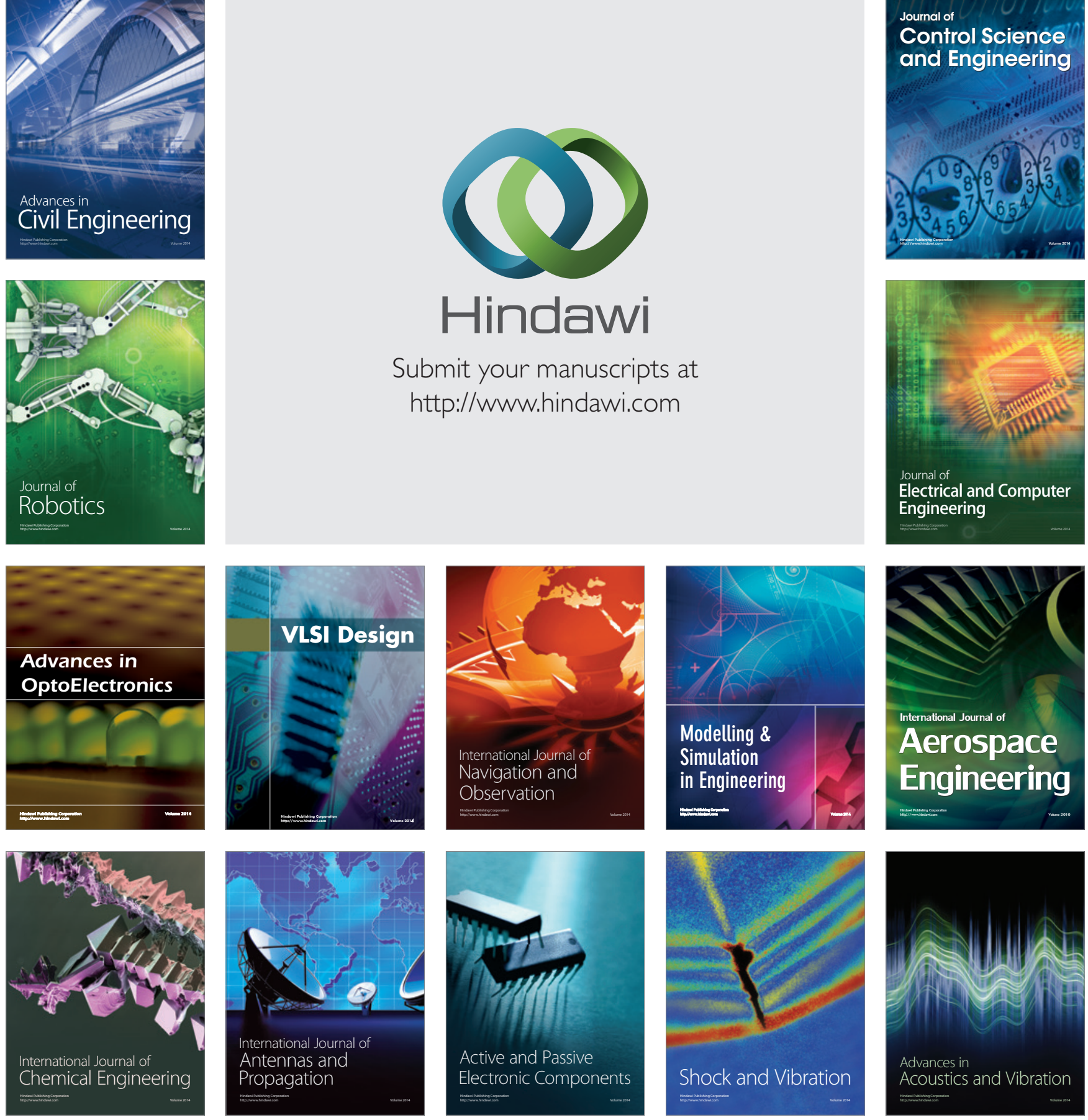